\title{
Panax ginseng C. A. Meyer as a potential therapeutic agent for organ fibrosis disease
}

\author{
Hao Liu', Chongning LV ${ }^{1,2}$ and Jincai Lu ${ }^{1,2^{*}}$
}

\begin{abstract}
Background: Ginseng (Panax ginseng C. A. Meyer), a representative Chinese herbal medicine, can improve the body's antioxidant and anti-inflammatory capacity. Recently, scientists have shifted emphasis towards the initial stages of different malignant diseases_-corresponding organ fibrosis and explored the essential role of P. ginseng in the treatment of fibrotic diseases.

Main body: In the first instance, the review generalizes the molecular mechanisms and common therapeutic methods of fibrosis. Next, due to the convenience and safety of individual medication, the research progress of ginseng extract and formulas in treating liver fibrosis, pulmonary fibrosis, myocardial fibrosis, and renal fibrosis has been systematically summarized. Finally, we describe active ingredients isolated from P. ginseng for their outstanding anti-fibrotic properties and further reveal the potential therapeutic prospect and limitations of $P$. ginseng in fibrotic diseases.

Conclusions: P. ginseng can be regarded as a valuable herbal medicine against fibrous tissue proliferation. Ginseng extract, derived formulas and monomers can inhibit the abundant deposition of extracellular matrix which caused by repeated damage and provide protection for fibrotic organs. Although the molecular mechanisms such as transforming growth factor $\beta$ signal transduction have been confirmed, future studies should still focus on exploring the underlying mechanisms of P. ginseng in treating fibrotic disease including the therapeutic targets of synergistic action of multiple components in P. ginseng. Moreover, it is also necessary to carry out clinical trial to evaluate the feasibility of $P$. ginseng in combination with common fibrosis drugs.
\end{abstract}

Keywords: Panax ginseng, Liver fibrosis, Pulmonary fibrosis, Myocardial fibrosis, Renal fibrosis, TGF- $\beta$ signaling pathway

\section{Background}

Each organ has its own function, maintaining the normal operation of life. However, due to certain known or unknown etiologies, the appearance of organ fibrosis disease (OFD) will suddenly break this steady state. Besides the etiologies that it is hard to diagnose correctly, patients with OFD often fail to show the corresponding clinical symptoms in time, which creates difficulties for exact treatment. OFD mainly includes

\footnotetext{
*Correspondence: jincailu@126.com

1 School of Traditional Chinese Materia Medica, Shenyang Pharmaceutical University, Shenyang 110006, PR China

Full list of author information is available at the end of the article
}

liver fibrosis (LF), pulmonary fibrosis (PF), myocardial fibrosis (MF), and renal fibrosis (RF), which is the initial process of serious tissue damage, organ necrosis, and major fatal diseases, dramatically shortening the lives of folks. Tissue or organ fibrosis is the leading cause of disability and death in many diseases. Statistics have shown that approximately $45 \%$ of the individuals who died of various diseases could be attributed to the results of tissue fiber hyperplasia in the developed countries [1], and even around the whole globe, organ failure caused by fibrotic diseases accounted for at least one-third of all deaths. When the tissues or organs are seriously destroyed for any unpredictable reasons, such 
as irritant, virus, radiation, and the damage is repetitive or exceed the self-repair capacity of cells, the entire process of OFD is initiated. Different organs have analogous fibrotic mechanism. Generally, during chronic injury, epithelial or endothelial cells secrete cytokines, for instance, tumor necrosis factor and interleukin (IL). Under this stimulation, fibroblasts will be activated and gradually transformed into myofibroblasts. After that, myofibroblasts composed of multiple sources, such as epithelial-mesenchymal transition (EMT) and resident fibroblast transformation, will abnormally proliferate and finally lead to the massive deposit of extracellular matrix (ECM), which further promote the development of fibrogenesis. Meanwhile, immune cells will produce cytokines such as transforming growth factor $\beta 1$ (TGF- $\beta$ )1, up-regulating the activity of myofibroblasts and boosting collagen synthesis (Fig. 1). In response to injury, the increase of fibrous connective tissue and interstitial cells and the decrease of parenchymal cells reveal the reasons of the destruction of organ structure and function [2,3]. It may be easy to eliminate the scars appear on the skin, but in liver, lung, heart, kidney, or other internal organs, the scars cannot be easily healed.
Therefore, determining suitable remedies for patients with OFD are necessary.

Panax ginseng C. A. Meyer is a household medicinal plant belonging to Araliaceae. "Panax" means all diseases can be cured in Greek, implicating the vital medicinal effect of $P$. ginseng. As an excellent preventive and therapeutic herb, $P$. ginseng has been applied medicinally for centuries in various diseases such as cancer, Alzheimer's disease, cognitive deficit and pulmonary disease [4-7]. It can also be regarded as a tonic and functional food to improve physical function and exercise capacity or a dietary supplement to neutralize the toxic and ameliorate unexpected side effects after chemotherapy [8]. Moreover, different types of $P$. ginseng such as sun-dried ginseng, white ginseng and red ginseng exhibit different therapeutic potential.

Recently, researches have revealed the curative effect of $P$. ginseng on severe late-stage disease. However, the systematic summary of $P$. ginseng for fibrosis, the inevitable stage of disease deterioration, is still insufficient. Here, this review aims at integrating the studies of $P$. ginseng therapy for fibrosis from main organs. Notably, holistic medication can maximum exert the therapeutic potential of herbal medicine through the synergistic action of

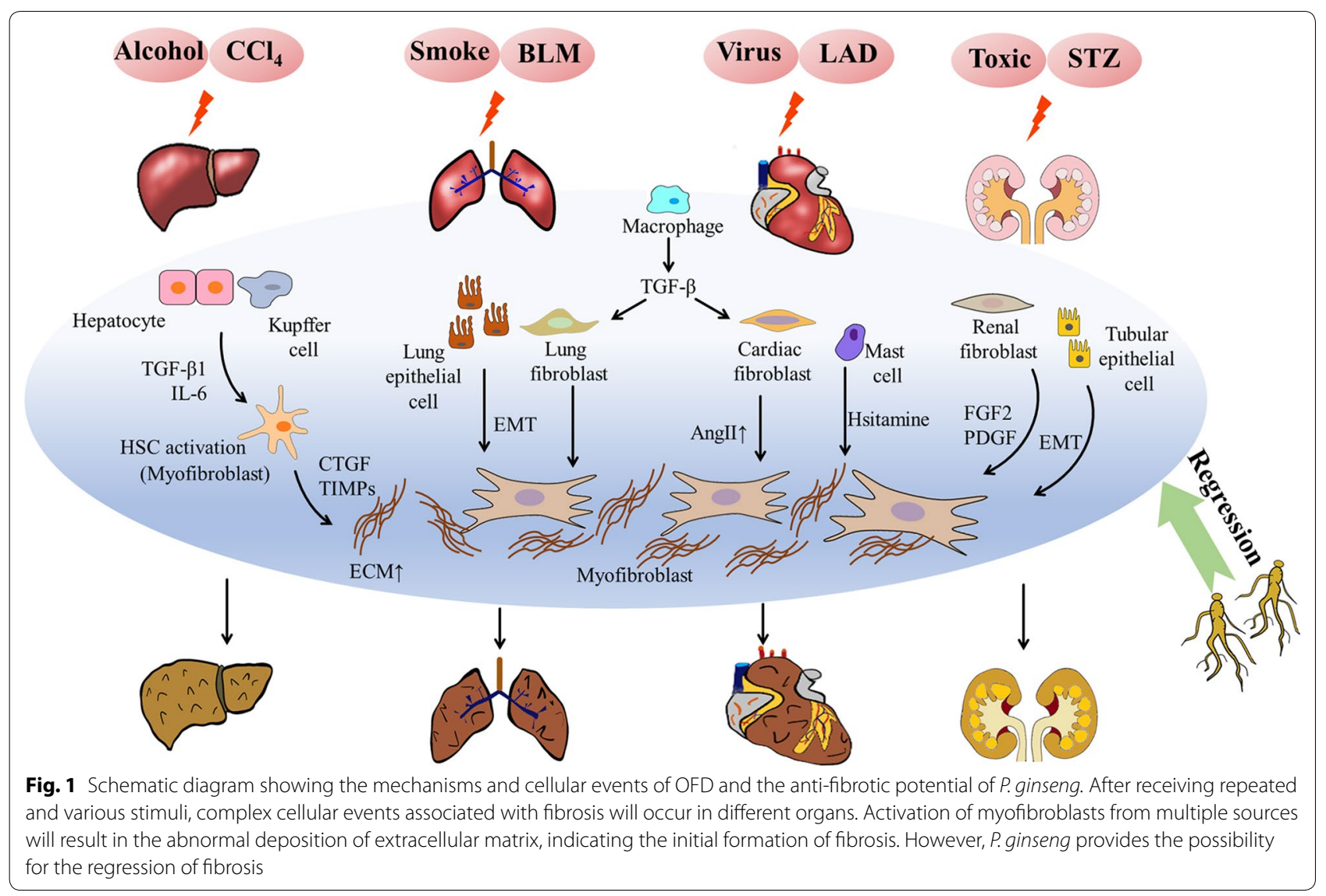


multi-component [9], so we primarily focus on ginseng extract and its derived formulas, but also consider ginseng bioactive compounds so as to further comprehensively develop the application of $P$. ginseng as an effective agent in the treatment of fibrotic diseases.

\section{Therapeutic strategies against OFD}

Many appropriate remedies have been carried out to fibrosis intervention. Surgery can be used to remove local lesions, but not diffuse fibrosis. Also, organ transplantation is applicable for advanced fibrotic individuals. Unfortunately, it often shows high probability of organ rejection and serious complications [10]. Expelling the pathogeny is one of the most efficient approaches in treating fibrosis. After alcohol withdrawal, the clinical performance and histopathological characteristics of patient will be evidently improved, which means the control of fibrosis in liver [11].

Drug therapy has always been regarded as the dominant intervention for OFD. However, there is still no synthetic drug that can completely avoid side effects while exerting efficacy throughout the treatment process. Oral administration of pirfenidone (PFD) and nintedanib (NDB), the mainstream synthetic drugs for fibrosis, often induces hypersensitivity, nausea, fatigue, or other adverse reactions and significantly increase aspartate aminotransferase (AST) and alanine aminotransferase (ALT) in serum, implying liver function damage. PF patients may experience repeated diarrhea and gastrointestinal disorders after taking NDB, resulting in premature therapy discontinuation [12]. For hepatic fibrosis caused by schistosomiasis, praziquantel has a limitation that it often causes abdominal pain and can hardly kill immature worms at a specified dose [13]. Tenofovir and entecavir, the resultful antiviral drugs recommended by World Health Organization (WHO), act on hepatic fibrosis caused by hepatitis B virus, whereas lactic acidosis may be developed in patients with impaired liver function during therapy [14]. Calcium channel blocker, angiotensin type 1 receptor antagonist and angiotensin converting enzyme inhibitor also has unpredictable side effect in the treatment of MF $[15,16]$.

Most of the methods of treating fibrosis have two nonnegligible issues: toxicity and unpleasant side effects. Conversely, natural products have received attention as a better strategy for fibrosis due to its particular advantages of "green therapy" [17]. Herbal medicine was generally exploited to charm away fibrosis with satisfactory results long ago, especially in Korea, Japan, and China [18, 19]. Cheap and easily available herbs instead of synthetic drugs are used as alternative medicine in underdeveloped areas to basically guarantee fibrosis treatment. Fuzheng Huayu, a herbal medicine preparations which has finished Phase II clinical trials authorized by the U.S. Food and Drug Administration, has been proven to lighten LF by reducing $\alpha$-smooth muscle actin ( $\alpha$-SMA) expression, activating liver natural killer cells and producing interferon-gamma [20]. Similarly, Si-Miao-Yong-An decoction (SMYAD) can restrain serine-threonine kinase Akt (AKT) and p38 mitogen-activated protein kinase (MAPK) pathway expression to dramatically reverse MF [21]. Additionally, small molecule compounds also provide vital therapeutic clues in OFD [22]. The potential of antiinflammatory and anti-fibrosis of hesperidin derivative (HD) has been confirmed, which is based on regulating liver injury markers and depending on hedgehogGlioma associated oncogene-1 signaling [23]. With the hepatoprotective effect, baicalin can decrease the levels of hyaluronic acid and procollagen type III in $\mathrm{CCl}_{4}$ model [24]. Paeoniflorin has a capacity to relieve the severity of IPF and control collagen synthesis through modulating TGF- $\beta /$ Smad pathway [25]. Triptolide has an outstanding effectiveness in PF induced by paraquat through adjusting the EMT progression of epithelial cells [26]. Crocin is able to suppress the inflammation and oxidative stress in isoprenaline-induced MF by triggering toll-like receptor (TLR) 4 and nuclear factor kappa B (NF-kB) signaling [27]. Astragaloside IV or its sapogenin cycloastragenol can be a candidate ingredient of fibrosis, which is linked to the inhibition of NLRP3 inflammasome [28].

\section{Effects of ginseng extract and formulas on OFD}

Long-term use of synthetic drug always leads to irreversible organ injury. However, more and more studies suggested that phytotherapy preserves organ function with few side effects and satisfying results. P. ginseng, the king of herbs, have been extensively investigated by Asian scholars. Ancient oriental healers decocted the root of $P$. ginseng with pure water as ginseng extract to cure a broad spectrum of diseases. They believed that this kind of natural and conventional method will give full play to the best nourishing effect of $P$. ginseng. Moreover, "Du Shen Tang", a traditional decoction that uses $P$. ginseng alone and many classical formulas that combines $P$. ginseng with other adjuvant herbs were developed. So far, the compound containing various types of $P$. ginseng such as sun died, red and white ginseng obtained by the simplest preparation method has been confirmed can be available to treat OFD. Moreover, not only can ginseng extract and its formulas show a positive therapeutic effect on skin fibrosis that appears outside, but also it has a certain effect in internal organ such as liver, lung, heart and kidney [29]. 


\section{Panax ginseng and LF}

Liver, a vital organ in the mammal body, is responsible for many critical functions such as biological metabolism, expulsion of toxins, which has been confirmed as an indispensable part of life. So losing a healthy liver signifies losing the ability of drug absorption and also losing the chance to live longer. Most of the occurrences of various liver diseases can be traced back to the continuous and uncontrolled development of LF. Numerous pathogenic factors such as hepatitis virus, alcohol, poisons and parasites can seriously damage hepatocytes and activate myofibroblasts, making the liver more susceptible to fibrogenesis and even cirrhosis. The activation of hepatic stellate cells (HSC) plays a vital key role in the mechanism of LF by irritating ECM accumulation. After the liver is stimulated by internal or external factors, TGF- $\beta$, IL and interferon-gamma will be released from hepatocytes, Kupffer cells and T cells, respectively, converting the quiescent HSC into active HSC. Thereafter, ECM with collagen in abundance begins to gather unconventionally. With the activation of HSC activity and the detrimental deposition of ECM, the fibrotic tissue has inevitably become increasingly dominant in the liver. If this condition develops out of control, it will ultimately give rise to cirrhosis and even liver cancer, endangering lives and hastening death [30].

Preliminary scientific studies have revealed that ginseng extract contributes to protect liver function from fibrosis and inhibits $\mathrm{CCl}_{4}$-induced liver damage in the established animal model by regulating TGF- $\beta 1 / \mathrm{Smad}$ signaling pathway which involves the suppression of the TGF- $\beta 1$, Smad2, Smad3 and IL-8 expression. Meanwhile, the modification of total cholesterol and collagen expression further verified this conclusion. In line with this model, another research also investigated that chemical toxic substances could inactivate liver enzyme activities and decrease biochemical parameters, which can be reversed after taking ginseng extract [31,32].

In addition to roots, other parts of $P$. ginseng have also been certified to confer excellent anti-fibrotic properties. Nam et al. [33] utilized a typical mild bile duct ligation model which caused liver damage by excessive producing bile acid to appraise the availability of ultrasonicated ginseng berry for LF treatment. Testing results demonstrated that the mechanisms by which ultrasonicated ginseng berry relieves LF is to inhibit the TLR4 expression and to soothe inflammation. Meanwhile, adventitious root culture of $P$. ginseng (ARCP) extracted with hot water possessed outstanding antioxidant ability after liver injury. Liver from ARCP-treated mice showed the decline of $\alpha-S M A$, which reflects the mitigation of HSC transformation on the other side. AST and ALT, the popular biomarkers to assess liver injury extent, will be released from liver to serum during the formation of LF. It can be speculated that mountain ginseng adventitious root extract restrains the liver damage and LF by diminishing the levels of those markers [34].

For observing and determining the abnormal lesions in the pathological process of LF accurately, it is necessary to select appropriate staining methods. Hematoxylin-eosin staining, one of the classic means for clinicopathologic analysis of LF, obtains distinct images of cell degeneration and necrosis. Furthermore, Masson trichromatic staining can apparently distinguish blue fiber hyperplastic tissues in the histopathology and immunohistochemical staining reflects the change of HSC, indirectly implying the degree of LF. A prior study has combined these three staining methods to intuitively exhibit the pathological differences between the groups, emphasizing the anti-fibrosis and hepatoprotective ability of ginseng essence, which boiled down to attenuate oxidative stress [35].

Red ginseng, the root of fresh ginseng after steaming and drying, has been clinically given more focus as the main type of $P$. ginseng and served as a candidate medicine for hypohepatia, fatigue, myocardial ischemia and other chronic diseases. Korean scientists are devoted to the research of Korean red ginseng (KRG) and found the crude extract of KRG acts as an antioxidant and protector in Hepatitis B-induced LF [36]. Apart from internal etiologies, KRG efficaciously mitigates inflammatory responses against acute LF which caused by physical factors such as Gamma irradiation or chemical factors such as $\mathrm{CCl}_{4}$ and alcohol [37-39].

\section{Panax ginseng and PF}

Accompanied by a high incidence, PF, also known as "chronic cancer", is the complication of many diseases such as COVID-19. In the long course of disease, patients often die of respiratory and circulatory failure, leading to the increase of suffering and the drop of living quality. PF is a hardly reversible lung disease with multiple etiologies, for example, smoking, mineral dust, silica and harmful gas inhalation. Remarkably, previous research has summarized that smokers are much more likely to catch pulmonary fibrosis than non-smokers. Regardless of the causes, the pathological features of PF generally made up of the disorder of lung structure, the damage of normal alveolar tissue, the activation of myofibroblasts and the aberrant deposition of collagen. The whole process of PF is mainly divided into four stages, namely, clotting/coagulation stage, inflammatory cell aggregation stage, myofibroblast proliferation stage and tissue remodeling stage [40]. No matter which cytokines are secreted at any stage, it will bring about the aggregation of ECM in the subsequent stage. 
Leaving aside the lung transplantation, the universally used drugs such as PFD and NDB can only alleviate the development of PF rather than reverse it fundamentally. These expensive synthetic chemicals, whose side effects probably occur at uncertain times, also become a key obstacle to the remedy of PF.

Ginseng extract has been fully convinced to invigorate lung tissue and delay PF progression. By examining the changes of superoxide dismutase and malondialdehyde, Jang et al. [41] found that intragastric administration of high dose ginseng extract could resist oxidative injury in radiation-induced PF. Abundant physiological abnormal cells and necrotic cells were detected after radiation, while ginseng extract pretreatment had shown a clear decrease in the immunoreactivity of TGF- $\beta 1$ and 4-hydroxynonenal in lung, exhibiting the positive impact on PF.

Owing to the excellent properties, Chinese herbal formulas with $P$. ginseng as sovereign drug are manifested to be a healing approach for PF. Renshen Pingfei Decoction contributes to the amelioration of PF in bleomycin (BLM)-damaged rats. In lung of treatment, hydroxyproline, a leading component of collagen, was progressively lower, which indirectly explained the decline of collagen synthesis. The mechanism as well as comprises interfering TGF- $\beta 1 /$ Smad3 level [42]. Bai et al. [43] carried out an exploratory experiment to evaluate whether Jinshui Huanxian formula (JHF), an empirical recipe encompassing $P$. ginseng and other auxiliary herbs, is valuable for $\mathrm{PF}$. They found gavage administration of JHF recovered lung function parameters such as forced vital capacity and lowered the levels of oxidative stress mediators by upregulating Nrf2 signaling in PF rats, which is consistent with the result of PFD. Additionly, the effect of Shenge Yangfei Capsules (SGYC) in reversing the pathophysiological changes and the deterioration of lung tissue was reported by Jia et al [44]. Compared with BLM-induced PF model, the expression of the monoamine and TGF- $\beta 1$ was effectively inhibited by the positive drug dexamethasone and SGYC treatments, which are concerned with the decrease of inflammatory cytokines and ECM deposition.

Recent clinical research indicated the conventional drug used to treat PF such as glucocorticoids seemingly cannot give a satisfactory answer. Zhang et al [45]. compared a new $P$. ginseng formula which can strengthening Qi and replenishing lung (DSQRL) and prednisolone in the treatment of PF. The normalization of biochemical indicators, behavior and histological appearance provided a possibility which DSQRL may instead of glucocorticoids in PF clinical treatment. Interesting, the combined therapy of DSQRL with prednisolone involves complex drug interactions, leading the decrease of curative effect.

\section{Panax ginseng and MF}

MF plays a pivotal role in cardiovascular disease which has been identified as the leading cause of death in all humanity. By reason of the lack of regenerative capacity like hepatocytes, the pivotal repair procedure of cardiomyocytes in response to cardiovascular damage is mainly manifested as MF. As the component of cardiac remodeling, MF is an abnormal pathologic change in heart, which is essentially characterized by the excess deposition of ECM between cardiomyocytes and it can also induce various heart diseases such as heart failure, sudden cardiac death and arrhythmia. The mainstream regards that there are two essential origins of MF: largearea myocardial cell death after myocardial infarction and the interstitial fibrosis. No matter which origin, with the continuous release of fibrogenic cytokines, cardiac myofibroblasts from multiple sources such as EMT and resident fibroblasts are activated by pressure overload, myocardial injury or other stimulant to proliferate in quantity [46].

Research on the heart protection of $P$. ginseng has lasted for more than half a century. Recently, Zhang et al. [47] demonstrated that ginseng crude extract represented antioxidant action to reverse the evolution of MF. The reduction of the left ventricular relative weight in ginseng group signified the breakdown of fibrotic tissue and the amelioration of MF. Moreover, ginseng treatment has no significant difference in ventricular mass indexes and oxidative stress markers with captopril, a common angiotensin converting enzyme inhibitor to treat MF. Similarly, KRG extract evidently enhanced myocardial function and relieved the severity of fibrosis in isoproterenol induced cardiac injury, which contains multiple mechanisms such as inhibited the expression of caspase- 3 and TNF- $\alpha$, antioxidative stress, reduced the water content of heart and protected cardiac cell membranes [48].

Shensong Yangxin Capsule, a prominent Chinese patent medicine rich in $P$. ginseng for treating arrhythmia, constitutes one of the contributing medicines for MF treatment. Treatment of MF with Shensong Yangxin Capsule downregulated the expression of TGF- $\beta 1$, MMP9 , and collagen I and III, suppressed the transformation of fibroblasts to myofibroblasts, mitigated left atrial fibrosis and indirectly diminished the incidence of atrial fibrillation [49]. Streptozotocin (STZ) injection and ligating left anterior descending coronary artery (LAD), both of which may generate acute MF. Previous experiments proved Tongxinluo (TXL), a classical TCMF followed collateral disease theory, resulted in a significant effect in the two prevailing methods for MF model establishment. TXL can downregulate the expression of MMP-2, -9 , TGF- $\beta 1$ and Smad3 and upregulate the expression of Smad7 in vivo. It can also downregulate the expression 
of hypoxia inducible factor-1a and upregulate the expression of neuregulins-1, AKT, phosphorylation of ErbB2, ErbB4 in vitro, thereby restraining of hypoxia-induced EMT [50].

Furthermore, many studies implicated that Shengmai San/Yin provided a therapeutic strategy in atrial fibrillation, cardiac toxicity and myocardial dysfunction that caused by LAD, doxorubicin and diabetes, respectively, which result from the restrain of MF deterioration. Correlation biological mechanisms that Shengmai San/Yin exhibited its anti-fibrosis merits covers upregulating connexin expression, inhibiting PICP, PIIINP expression and TGF- $\beta$ dependent pathway $[51,52]$. On the basis of Shengmai San, YiQiFuMai Powder contained four additional compounds, which possesses the advanced freeze-drying technology, displayed the potential in MF treatment and ventricular remodeling. Its underlying mechanism may be linked to the intracellular signal transduction of MAPKs [53].

\section{Panax ginseng and RF}

Similar to the fibrosis in other organs, RF may occur after severe kidney injury. High blood pressure, diabetes, drug poisoning and other risk factors are considered to be responsible for RF. With the development of RF, the function of kidney to excrete metabolic waste, regulate electrolyte concentration and maintain acid-base balance gradually disappears. Glomerulosclerosis and tubulointerstitial fibrosis, two principal pathological appearances of RF, have been testified to be the detrimental process leading to renal failure, including plenty of complex mechanisms. The crucial mechanism is that, during the stage of continuously renal injury, the activation of myofibroblasts from different sources will result in the abnormal amassing of ECM, accelerating the development of RF. Thereinto, in addition to interstitial fibroblasts transformation, the EMT that tubular epithelial cells transformed into myofibroblasts has also been demonstrated to be the basic source of myofibroblasts [54]. If the reversal method misses the optimal treatment period, RF will soon develop into the final phase that uremia, which will never be reversed, meaning that patients can only extend their lives slightly by dialysis.

Kalkan et al. [55] indicated that $P$. ginseng exhibited a protective action in kidney damage and fibrosis caused by broad-spectrum antibiotic. Meanwhile, ginseng extract inhibited Bax expression to regulate renal apoptosis after oral administration of gentamicin sulphate. The abatement of nephrotoxicity highlighted that treatment with $P$. ginseng may have the ability to alleviate RF caused by biological drugs. As the diet structure changes, long-term ingestion of high purine food will promote the development of kidney disease. Choi et al. [56] found sun ginseng, a species of steamed ginseng, obviously ameliorated adenine-induced renal injury by limiting the deterioration of RF, renal hypertrophy, and renal edema to a certain extent, which was in reference to the reduction of urea nitrogen and creatinine. In present findings on other types of $P$. ginseng, red ginseng was described to be suitable for both diabetes and serious comorbidity such as diabetic nephropathy caused by RF. Karunasagara et al. [57] constructed a hyperglycemia-induced diabetic nephropathy model and suggested KRG treatment modulated fibrotic and inflammatory mediators such as TGF$\beta 1$, kidney injury molecule- 1 , and advanced glycation end products and speeded up the process of autophagy to recover RF. Lim et al. [58] demonstrated that KRG restored e-cadherin, $\alpha$-SMA and TGF- $\beta 1$ expression in the treatment of RF. Oral therapy of KRG power upregulated Klotho expression in tacrolimus-induced renal injury and diminished reactive oxygen species production in mitochondrion. In addition, the red ginseng extract processed with pectin lyase also has been documented remodel renal structure and function in STZinduced diabetic model [59].

Besides heart protective effect, TXL also been authenticated to has curative value in RF. After TXL intervention, the aberrant expression of fibronectin returned to normal in diabetic nephropathy. At the same time, the recovery pathological staining and blood indexes intuitively explained TXL can control TGF- $\beta 1$ transfer from glomerular mesangial cells to glomerular endothelial cells via exosomes [60]. Additionally, the summary of experimental procedures and mechanisms of $P$. ginseng against OFD are recapitulated in Table 1 to explain for a detailed understanding.

\section{Effects of ginseng components on OFD}

It is difficult to determine whether the efficacy of $P$. ginseng results in the synergistic interactions of multiple components or the single action of main component. However, bioactive ingredients isolated from $P$. ginseng such as saponin, polysaccharide, sesquiterpenoid and protein have been demonstrated to be a promising treatment for fibrosis (Table 2).

Currently, tremendous amounts of research illustrated the anti-fibrotic pharmacological action of $P$. ginseng is associated with ginsenosides [61]. Total ginsenoside, an extensively studied ingredient that isolated from ginseng extract with $60 \%$ ethanol following Chinese Pharmacopoeia, is deemed to be one of the popular candidates for fibrosis-associated diseases. Moreover, individual ginsenosides isolated from total ginsenoside such as $\mathrm{Rg}_{1}[62-$ 65], $\mathrm{Rb}_{1}$ [66-68], $\operatorname{Re}$ [69], $\mathrm{Rg}_{3}$ [70], $\mathrm{Mc}_{1}$ [71] also exert their anti-fibrosis potential (Fig. 2). 
Table 1 Therapeutic mechanism and anti-fibrosis actions of ginseng extract and formula

\begin{tabular}{|c|c|c|c|c|c|c|}
\hline Sample & Inducing & Model & Animal groups & Therapeutic mechanisms & Organ & Ref. \\
\hline $\begin{array}{l}\text { Ginseng extract } \\
\text { (GE) }\end{array}$ & $\mathrm{CCl}_{4}$ & Wistar rat & $\begin{array}{l}\text { (1) Control; (2) } \mathrm{CCl}_{4 ;} \text { (3) GE } \\
(400 \mathrm{mg} / \mathrm{kg}) ; \\
\text { 4. } \mathrm{CCl}_{4}+\mathrm{GE}(400 \mathrm{mg} / \mathrm{kg})\end{array}$ & $\begin{array}{l}\downarrow T G, \text { TC, LDL, AST, ALT, TGF- } \\
\beta, \text { T RR-I, TRR-II, Smad2, -3, } \\
-4, \text { MMP2, -9, col 1a2, col } \\
\text { 3a1, IL-8 } \\
\uparrow H D L, ~ I L-10\end{array}$ & Liver & 31 \\
\hline Ginseng & $\mathrm{CCl}_{4}$ & Wistar rat & $\begin{array}{l}\text { (1) Control; (2) } \mathrm{CCl}_{4} ;(3) \\
\text { Ginseng }(300 \mathrm{mg} / \mathrm{kg}) \text {; } \\
\text { 4. } \mathrm{CCl}_{4}+\text { Ginseng }(300 \mathrm{mg} / \\
\text { kg) }\end{array}$ & $\begin{array}{l}\downarrow \text { AST, ALT, GGT, TG, TC, Glu, } \\
\text { caspase-3, CD } 68^{+} \\
\uparrow T P, \text { Calcium }\end{array}$ & Liver & 32 \\
\hline $\begin{array}{l}\text { Ultrasound ginseng berry } \\
\text { extract (UGBE) }\end{array}$ & MBDL & SD rat & $\begin{array}{l}\text { (1) Control; (2) Sham; (3) } \\
\text { MBDL; } \\
\text { 4. MBDL+ Silymarin } \\
(150 \mathrm{mg} / \mathrm{kg}) ; \\
\text { 5. MBDL+GBE }(250 \mathrm{mg} / \mathrm{kg}) \text {; } \\
\text { 6. MBDL + UGBE }(100,250 \text {; } \\
500 \mathrm{mg} / \mathrm{kg})\end{array}$ & $\begin{array}{l}\downarrow \text { AST, ALT, Ammonia, TNF-a, } \\
\text { NF-KB, iNOS, NO, Myd88, } \\
\text { TLR4 } \\
\uparrow S O D, \text { GPX, CAT, HO-1 }\end{array}$ & Liver & 33 \\
\hline $\begin{array}{l}\text { Tissue culture raised moun- } \\
\text { tain ginseng adventitious } \\
\text { root (TCMGAR) }\end{array}$ & $\mathrm{CCl}_{4}$ & SD rat & $\begin{array}{l}\text { (1) Control; (2) } \mathrm{CCl}_{4 i} \\
\text { 3. Cultivated ginseng } \\
(100 \mathrm{mg} / \mathrm{kg}) ; \\
\text { 4. TCMGAR (30, 100, } \\
300 \mathrm{mg} / \mathrm{kg})\end{array}$ & $\begin{array}{l}\downarrow A S T, A L T, A L P, M D A \\
\uparrow G P X\end{array}$ & Liver & 34 \\
\hline Ginseng essence (GE) & $\mathrm{CCl}_{4}$ & Wistar rat & $\begin{array}{l}\text { (1) Control; (2) } \mathrm{CCl}_{4} ; \\
\text { 3. } \mathrm{CCl}_{4}+\text { Silymarin }(0.5 \mathrm{~g} / \\
\mathrm{kg}_{i} \\
\text { 4. CCl } \\
\quad 3.125 \mathrm{~g} / \mathrm{kg})\end{array}$ & $\begin{array}{l}\downarrow \text { AST, ALT } \\
\uparrow \text { GPX, GSH, GRd, GST, SOD, } \\
\text { CAT, Albumin }\end{array}$ & Liver & 35 \\
\hline Korean red ginseng (KRG) & $\gamma \mid \mathrm{R}$ & C57BL/6 mouse & $\begin{array}{l}\text { (1) Control; (2) yIR; } \\
\text { 3. } \gamma \mathrm{IR}+\mathrm{KRG}(10,50 \mathrm{mg} / \mathrm{kg})\end{array}$ & $\begin{array}{l}\downarrow \text { AST, ALT, GGT, ALP, COX-2, } \\
\text { TGF- } \beta 1, \text { ERK, NF-KB Nrf2 } \\
\uparrow H O-1\end{array}$ & Liver & 37 \\
\hline Red ginseng extract (RGE) & $\mathrm{CCl}_{4}$ & C57BL/6 mouse & $\begin{array}{l}\text { (1) Control; (2) } \mathrm{CCl}_{4} ; \\
\text { 3. CCl }+\mathrm{RGE}(30,100 \text {; } \\
300 \mathrm{mg} / \mathrm{kg})\end{array}$ & $\begin{array}{l}\downarrow \text { ALT, AST, TGF- } \beta 1, \text { PAl-1, } \\
\quad \mathrm{a}-\mathrm{SMA}\end{array}$ & Liver & 38 \\
\hline Korean red ginseng (KRG) & Alcohol & SD rat & $\begin{array}{l}\text { (1) Control; (2) Alcohol; } \\
\text { 3. Alcohol + KRG (125, } \\
250 \text { mg/kg) }\end{array}$ & $\begin{array}{l}\downarrow T G, \text { TC, SREBP-1c, FAS, ACC, } \\
\text { Leptin, HSL } \\
\uparrow C P T-1 a, p-A M P K, \text { PPAR- } \gamma, \\
\text { Adiponectin }\end{array}$ & Liver & 39 \\
\hline Panax ginseng extract (PEG) & $\mathbb{R}$ & C57BL/6N mouse & $\begin{array}{l}\text { (1) Control; (2) IR; } \\
\text { 3. IR + melatonin ( } 20 \mathrm{mg} / \\
\text { kg); } \\
\text { 4. IR+ PEG }(20,50,100 \mathrm{mg} / \\
\text { kg) }\end{array}$ & $\begin{array}{l}\downarrow M D A, T G F-\beta 1, \text { TNA- } a \\
\uparrow S O D, C A T, G S H\end{array}$ & Lung & 41 \\
\hline Renshen Pingfei Decoction & BLM & SD rat & $\begin{array}{l}\text { (1) Control; (2) BLM; } \\
\text { 3. BLM + prednisone } \\
\text { acetate }(5.4 \mathrm{mg} / \mathrm{kg}) \\
\text { 4. BLM + RPFS }(0.65 \mathrm{~g} / 100 \mathrm{~g})\end{array}$ & $\begin{array}{l}\downarrow R I, \text { Smad3, TGF- } \beta \text {, NF-KB, } \\
\text { HYP, MDA } \\
\uparrow F V C, T L C, \text { Cchord, SOD }\end{array}$ & Lung & 42 \\
\hline $\begin{array}{l}\text { Jinshui Huanxian formula } \\
\text { (JHF) }\end{array}$ & BLM & SD rat & $\begin{array}{l}\text { (1) Control; (2) BLM; (3) } \\
\text { BLM + PFD (50 mg/kg) } \\
\text { 4. BLM+JHF (10.8 g/kg) }\end{array}$ & $\begin{array}{l}\downarrow \text { a-SMA, col-I, col-III, HYP, } \\
\text { MDA, MPO, NOX4 } \\
\text { 个FVC, T-SOD, GSH, CAT, } \\
\text { Nrf2a }\end{array}$ & Lung & 43 \\
\hline $\begin{array}{l}\text { Shenge Yangfei Capsules } \\
\text { (SGYC) }\end{array}$ & BLM & Wistar rat & $\begin{array}{l}\text { (1) Control; (2) BLM; } \\
\text { 3. BLM + dexamethasone } \\
\text { ( } 5 \mathrm{mg} / \mathrm{kg}) ; \\
\text { 4. BLM + SGYC }(70,420 \text {, } \\
850 \mathrm{mg} / \mathrm{kg})\end{array}$ & $\downarrow M A O, T G F-\beta 1$ & Lung & 44 \\
\hline $\begin{array}{l}\text { Decoction for } \\
\text { Strengthening Qi and } \\
\text { Replenishing Lung } \\
\text { (DSQRL) }\end{array}$ & $\mathrm{CCl}_{4}$ & SD rat & $\begin{array}{l}\text { (1) Control; }(2) \mathrm{CCl}_{4} ; \\
\text { 3. } \mathrm{CCl}_{4}+\text { prednisolone } \\
(6.35 \mathrm{mg} / \mathrm{kg}) ; \\
\text { 4. } \mathrm{CCl}_{4}+\text { DSQRL }(7.7 \mathrm{~g} / \mathrm{kg}) ; \\
\text { 5. } \mathrm{CCl}_{4}+\text { Predniso- } \\
\text { lone+DSQRL }\end{array}$ & $\uparrow H Y P, T G F-\beta 1, \mathrm{Col}$ & lung & 45 \\
\hline
\end{tabular}


Table 1 (continued)

\begin{tabular}{|c|c|c|c|c|c|c|}
\hline Sample & Inducing & Model & Animal groups & Therapeutic mechanisms & Organ & Ref. \\
\hline Ginseng mixture & ISO & Wistar rat & $\begin{array}{l}\text { (1) Control; (2) ISO; } \\
\text { 3. ISO + Captopril } \\
\text { (0.45 mg/2 mL); } \\
\text { 4. ISO+ ginseng mixture } \\
(20,80 \mathrm{~g} / \mathrm{kg})\end{array}$ & $\begin{array}{l}\downarrow \mathrm{HYP}, \mathrm{CK}, \mathrm{LDH}, \mathrm{H}_{2} \mathrm{O}_{2} \\
\uparrow C A T, \mathrm{GPX}\end{array}$ & Heart & 47 \\
\hline Korean Red Ginseng (KRG) & ISO & Wistar rat & $\begin{array}{l}\text { (1) Control; (2) ISO; (3) KRG } \\
\quad(500 \mathrm{mg} / \mathrm{kg}) ; \\
\text { 4. ISO+KRG }(250,500 \mathrm{mg} / \\
\text { kg) }\end{array}$ & $\begin{array}{l}\downarrow \text { HYP, LDH, AST, ALT, } \\
\text { caspase-3, MDA, MPO, } \\
\text { CK-MB, TNF-a } \\
\text { } \text { LVSP, SOD, CAT, GPX }\end{array}$ & Heart & 48 \\
\hline Shensong Yangxin (SSYX) & LAD & SD rat & $\begin{array}{l}\text { (1) Sham; (2) LAD; } \\
\text { 3. LAD + SSYX (600 mg/kg) }\end{array}$ & $\begin{array}{l}\downarrow \text { col I, col III, a-SMA, TIMP-1, } \\
\text { MMP-9, TGF- } \beta 1 \\
\uparrow L V E F, \text { LVFS }\end{array}$ & Heart & 49 \\
\hline Tongxinluo (TXL) & LAD & SD rat & $\begin{array}{l}\text { (1) Sham; (2) LAD; } \\
\text { 3. LAD + benazepril }(10 \mathrm{mg} / \\
\text { kg); } \\
\text { 4. LAD + TXL }(0.2,0.4,0.8 \mathrm{~g} / \\
\text { kg) }\end{array}$ & $\begin{array}{l}\downarrow \text { col II, col III, MMP-2, }-9, \\
\text { a-SMA, FSP-1 } \\
\uparrow L V E F, \text { LVFS, CD31, VE- } \\
\text { cadherin }\end{array}$ & Heart & 50 \\
\hline Shengmai San (SMS) & LAD & SD rat & $\begin{array}{l}\text { (1) Sham; (2) LAD; (3) } \\
\text { LAD+ SMS (500 mg/kg) }\end{array}$ & $\begin{array}{l}\downarrow \text { col I, col III, IL-6, MCP-1, } \\
\text { TNF-a, BNP, TGF- } \beta 1, \text { MMP- } \\
\text { 9, a-SMA } \\
\text { 个LVEF, LVFS, Cx43, Cx40, } \\
\text { TIMP-1 }\end{array}$ & Heart & 51 \\
\hline Shengmai Yin (SMY) & Doxorubicin (DOX) & SD rat & $\begin{array}{l}\text { (1) Control; (2) DOX; } \\
\text { 3. DOX + SMY (8.35, 16.7, } \\
33.4 \mathrm{~g} / \mathrm{kg})\end{array}$ & $\begin{array}{l}\downarrow \text { BNP, CK-MB, TLR2, MCP-1, } \\
\text { INF- } \gamma, \text { IL-6, PICP, PIIINP } \\
\uparrow L V E F\end{array}$ & Heart & 52 \\
\hline YiQiFuMai & LAD & ICR mouse & $\begin{array}{l}\text { (1) Control; (2) LAD; } \\
\text { 3. LAD + metoprolol } \\
\text { (5.14 mg/kg); } \\
\text { 4. LAD+YQFM }(0.13,0.26 \text {, } \\
0.53 \mathrm{~g} / \mathrm{kg})\end{array}$ & $\begin{array}{l}\downarrow M D A, \text { LDH, CK, HYP, p38, } \\
\text { JNK, ErK1/2, PIIINP, } \\
\text { NT-proBNP } \\
\text { 个LVEF, LVFS }\end{array}$ & Heart & 53 \\
\hline Ginseng & gentamicin sulphate (GS) & SD rat & $\begin{array}{l}\text { (1) Control; (2) GS; } \\
\text { 3. GS + KRG (100, } 200 \mathrm{mg} / \\
\text { kg) }\end{array}$ & $\begin{array}{c}\downarrow \text { Cre, Urea, BUN, AST, ALT, } \\
\text { GGT, TC, TG, Glu, TP, Bax, } \\
\uparrow \text { Bcl-2 Calcium, Phosphorus }\end{array}$ & Kidney & 55 \\
\hline Sun Ginseng (SG) & adenine & SD rat & $\begin{array}{l}\text { (1) Control; (2) Adenine; } \\
\text { 3. Adenine + SG }(0.5,1.0 \mathrm{~g} / \\
\text { kg) }\end{array}$ & $\begin{array}{l}\downarrow S c r, B U N, \text { phosphate in } \\
\text { serum, calcium in urine } \\
\uparrow \text { calcium in serum, phos- } \\
\text { phate in urine }\end{array}$ & Kidney & 56 \\
\hline Korean red ginseng (KRG) & STZ & SD rat & $\begin{array}{l}\text { (1) Control; (2) STZ; } \\
\text { 3. STZ+ losartan (100 mg/ } \\
\text { kg/); } \\
\text { 4. STZ+KRG }(250,500 \mathrm{mg} / \\
\text { kg) }\end{array}$ & $\begin{array}{l}\downarrow \text { blood glucose, HbA1c, } \\
\text { BUN, a-SMA, TGF- } \beta 1, \text { KIM1, } \\
\text { AGE, p62, mTOR } \\
\uparrow L C 3, \text { ATG7 }\end{array}$ & Kidney & 57 \\
\hline $\begin{array}{l}\text { Korean red ginseng } \\
\text { powder (KRGP) }\end{array}$ & tacrolimus & BALB/c mouse & $\begin{array}{l}\text { (1) Control; (2) KRGP }(0.2 \mathrm{~g} \text { / } \\
\text { kg); } \\
\text { 3. tacrolimus; } \\
\text { 4. tacrolimus + KRGP }\end{array}$ & $\begin{array}{l}\downarrow \text { Scr, a-SMA, TGF- } \beta \text {, } \\
\text { 8-OHdG, PI3K, p-AKT, } \\
\text { FoxO3a, ROS } \\
\text { 个Plasma Klotho, E-CA, } \\
\text { MnSOD }\end{array}$ & Kidney & 58 \\
\hline GS-E3D & STZ & SD rat & $\begin{array}{l}\text { 1.Control; 2. STZ; } \\
\text { 3. STZ+ GS-E3D }(20,50 \text {, } \\
100 \mathrm{mg} / \mathrm{kg})\end{array}$ & $\begin{array}{l}\downarrow \text { albuminuria, } 8-O H d G \text { in } \\
\text { urine, AGE in urine, a-SMA }\end{array}$ & Kidney & 59 \\
\hline $\mathrm{TXL}$ & diabetes & KK-Ay mouse & $\begin{array}{l}\text { 1. Control: C57BL/6 mouse; } \\
\text { 2. Model: KK-Ay mouse; } \\
\text { 3. KK-Ay mice + TXL ( } 0.75 \text { g/ } \\
\text { kg) }\end{array}$ & $\begin{array}{l}\downarrow T G F-\beta 1, \text { Smad3, col IV, FN, } \\
\uparrow C c r\end{array}$ & Kidney & 60 \\
\hline
\end{tabular}

Besides ginsenoside, ginseng polysaccharide, a biological reaction modifier, has been widely concerned in recent years. Ginsan has been corroborated to act as a therapeutic agent to alleviate symptom and establish prevention when it was used to treat Sprague-Dawley rats with PF. Whether in vivo or in vitro, the experimental results conjointly illustrated that ginsan can maintain the balance of PF-related protein expression in both 
Table 2 Therapeutic mechanism and anti-fibrosis actions of ginseng components

\begin{tabular}{|c|c|c|c|c|c|c|}
\hline Sample & Inducing & Model & Animal groups & Therapeutic mechanisms & Organ & Ref. \\
\hline $\mathrm{G}-\mathrm{Rg}_{1}$ & $\mathrm{CCl}_{4}, \mathrm{BLM}, \mathrm{DOX}, \mathrm{UUO}$ & $\begin{array}{l}\text { SD rat } \\
\text { Wistar rats }\end{array}$ & $\begin{array}{l}\text { (1) Control; (2) } \mathrm{CCl}_{4}, \mathrm{BLM} \text {, } \\
\mathrm{TAC}, \cup \cup \mathrm{U}^{\prime} \\
\text { 3. } \mathrm{CCl}+\mathrm{Rg}_{1}(10,20 \text {, } \\
40 \mathrm{mg} / \mathrm{kg}) ; \\
\text { 4. } \mathrm{BLM}+\mathrm{prednisone} \\
\text { acetate }(5 \mathrm{mg} / \mathrm{kg}) ; \\
\text { BLM + } \mathrm{Rg}_{1}(18,36,72 \mathrm{mg} / \\
\mathrm{kg}) ; \\
\text { 5. } \mathrm{TAC}+\mathrm{Rg}_{1}(10 \mathrm{mg} / \mathrm{kg}) ; \\
\text { 6. } \cup \cup O+\mathrm{Rg}_{1}(12.5,25 \\
50 \mathrm{mg} / \mathrm{kg} / \mathrm{d})\end{array}$ & $\begin{array}{l}\downarrow \text { ALT, AST, LDH, ALP, HYP, } \\
\text { a-SMA, TGF- } \beta 1, \text { TSP-1, col } \\
\text { l, fibronectin, p38MAPK } \\
\text { 个Nrf2, Cav-1, ED, FS, HIF-1, } \\
\text { p-Akt }\end{array}$ & Liver lung heart kidney & $62-65$ \\
\hline $\mathrm{G}-\mathrm{Rb}_{1}$ & $\mathrm{CCl}_{4}, \mathrm{AAC}, \mathrm{UUO}$ & SD rat & 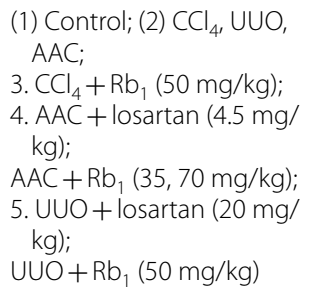 & $\begin{array}{l}\downarrow \text { AST, ALT, TG, HYP, TNF-a, } \\
\text { IL-1 } \beta, \text { PGE }_{2} \text {, sICAM-1, } \\
\text { p47phox, col I, fibronec- } \\
\text { tin, 8-OhdG, HO-1, ANF, } \\
\text { ACE, Ang II, AT1, TGF- } \beta \\
\text { 个IL-10 }\end{array}$ & Liver heart kidney & $66-68$ \\
\hline G-Re & ISO & Wistar rat & $\begin{array}{l}\text { (1) Control; (2) ISO; } \\
\text { 3. ISO+Re }(5,20 \text { mg/kg) }\end{array}$ & $\begin{array}{l}\downarrow \text { Smad3, col I, LVEDP, HYP } \\
\uparrow L V S P,+d p / d t\end{array}$ & Heart & 69 \\
\hline $\mathrm{G}-\mathrm{Rg}_{3}$ & $\begin{array}{l}\text { Thioacetamide } \\
\text { (TAA) }\end{array}$ & ICR mice & $\begin{array}{l}\text { (1) Control; (2) TAA; } \\
\text { 3. TAA+ } \operatorname{Rg}_{3}(5,10 \mathrm{mg} / \mathrm{kg})\end{array}$ & $\begin{array}{l}\downarrow \text { AST, ALT, CAT, } \\
\text { MDA,TGF- } \beta 1, a-S M A, p 62 \\
\uparrow S O D, G S H, P I 3 K, A K T, \\
\quad \text { mTOR }\end{array}$ & Liver & 70 \\
\hline Ginsan & BLM & C57BL/6 mouse & $\begin{array}{l}\text { (1) Control; (2) BLM; } \\
\text { 3. BLM + Ginsan (2 mg/kg) }\end{array}$ &  & lung & 72 \\
\hline $\begin{array}{l}\text { Sesquiterpenoids } \\
\text { from Panax } \\
\text { Ginseng } \\
\text { (SPG) }\end{array}$ & $\mathrm{CCl}_{4}$ & ICR mouse & $\begin{array}{l}\text { (1) Control; (2) } \mathrm{CCl}_{4 i} \\
\text { 3. } \mathrm{CCl}_{4}+\operatorname{SPG}(2.5,10 \mathrm{mg} / \\
\text { kg) }\end{array}$ & $\begin{array}{l}\downarrow \text { ALT, AST, MDA, TNF- } a, \\
\text { IL-1 } 1 \beta, \text { IL-6, JNK, ERK, } \\
\text { MAPK p38, NF-KB p65, } \\
\text { COX-2 } \\
\uparrow G S H, \text { SOD, CAT }\end{array}$ & liver & 74 \\
\hline
\end{tabular}

TGF- $\beta$-induced and BLM-induced models [72] (Fig. 3). Ginseng protein regulated oxidative stress-induced fibroblast proliferation though restraining collagen degradation and provided protection in antifibroblast photoaging damage [73]. Sesquiterpenoids that isolated from ginseng essential oil have been described to produce hepatoprotection in $\mathrm{CCl}_{4}$-damaged LF. The underlying mechanisms include antioxidant and anti-inflammatory, involving NF- $\kappa B$ and MAPK pathways [74].

The mainstream view is that the structure of compounds contributes to their pharmacological effects, so it is necessary to determine the purification and characterization methods of the ingredients of ginseng. Individual ginsenosides, which are classified as oleanolic acid type, dammarance type and ocotillon type triterpenoid saponin, can be isolated and purified from ginseng extract by macroporous adsorptive resins and silica gel. Based on spectral and chemical analysis, the chemical structure of the ginsenosides for OFD treatment have been characterized. Their anti-fibrosis effects in different organs rely on the definable structures. For example, $\mathrm{Rb}_{1}$ is belong to protopanaxadiol with four sugars, while $\operatorname{Re}$ is belong to protopanaxatriol with three sugars. After isolated from the ethanol-insoluble fraction of ginseng extract, ginsan was purified by gel and DEAE-sephadex column chromatography, respectively. According to the hydrolysis and derivatization analysis, ginsan consists of glucose, galactose, mannose and arabinose. Meanwhile, by NMR analysis, ginsan consists of $\alpha(1 \rightarrow 6)$ glucopyranoside and $\beta(2 \rightarrow 6)$ fructofuranoside. In addition, after purified by DEAE Sepharose Fast Flow, ginseng protein was further purified by Sephadex G-75 gel filtration column. It is composed of proteins with molecular weight of 27 and $13 \mathrm{kDa}$ which was characterized by SDS-PAGE. Sesquiterpenoids was obtained by supercritical $\mathrm{CO}_{2}$ extraction from $P$. ginseng. After analyzed by GC-MS, the chemical structure of the main sesquiterpenoids has been identified and shown in Fig. 2 . 


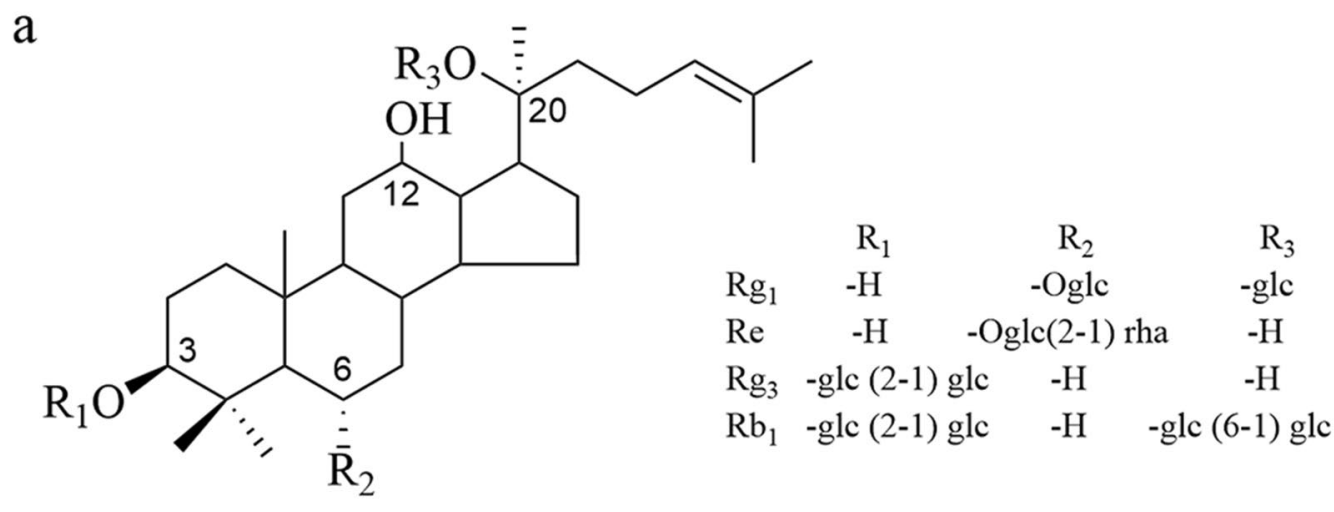

$\mathrm{b}$
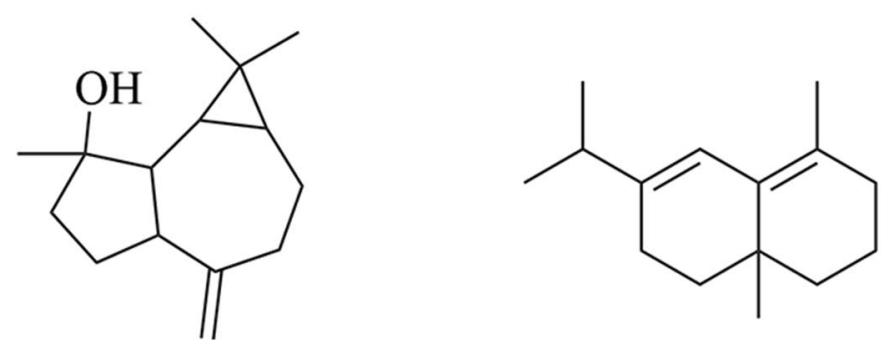

Fig. 2 Chemical Structure of the major anti-fibrosis individual components from P. ginseng. a Ginsenoside $\left(R g_{1}, R e, R_{3}, R b_{1}\right)$. b The major sesquiterpenoids from $P$. ginseng

\section{Conclusion and perspective}

Most of drug discovery paid more attention to the treatment of advanced disease, for instance, cirrhosis and uremia, which can hardly be cured fundamentally. But often overlooked is that, organ fibrosis is a necessary process for the development of most diseases. If it can be suppressed or reversed as much as possible, the serious condition will be alleviated or even resolved.

Many differences distinguish synthetic drugs and herbal medicines, from treatment cost to adverse reactions. Notably, only about $10 \%$ terrestrial plants have been studied in pharmacology, further indicating the prospect of herbal medicine in the discovery of antifibrosis [75]. With the irreplaceable medicinal value and obvious therapeutic effect, $P$. ginseng plays an increasingly significant role in the fibrotic prevention and rehabilitation and has proverbially been utilized to increase longevity. As an advantage to apply expediently, $P$. ginseng can be used independently or in combination with multiple herbs as herbal compounds, exhibiting multi-component or multi-herb combination characterizes, respectively. Whether ginseng extract or formulas, their therapeutic effect on the main organ fibrosis has been confirmed. Furthermore, saponin and polysaccharide or other monomers of ginseng exert anti-fibrosis actions by regulating fibrotic-related signal transduction pathways, which involves multiple mechanisms such as enhancing the self-healing ability of damaged cells, inhibiting fibroblast activation, promoting myofibroblast apoptosis and regulating inflammatory response. Although there may be more targets for the treatment of fibrosis in ginseng extract or formulas, a complex system of treatment, it is not as generally recognized as the ginseng monomers which have the clear structure.

It is universal believed $P$. ginseng can act as a dietary supplement or medicine to intervene disease progression. Meanwhile, synthetic drug or natural product combined with $P$. ginseng may be more advantageous than using them alone in fibrosis treatment [76]. Worth noting that drug combination has been proved to be clinical efficacy, especially in China where the integrated traditional and western medicine is widely used to treat fibrosis. Cooperation of the advantages may become one of the appropriate therapeutic methods for OFD. However, it is difficult to thoroughly determine the mechanism of drug combination, which attributes to the interaction of a wide range of complex components. In addition, $P$. ginseng can also alleviate the fibrosis caused by synthetic drugs such as omeprazole in the process of treating other diseases, although further clinical researches are needed to 


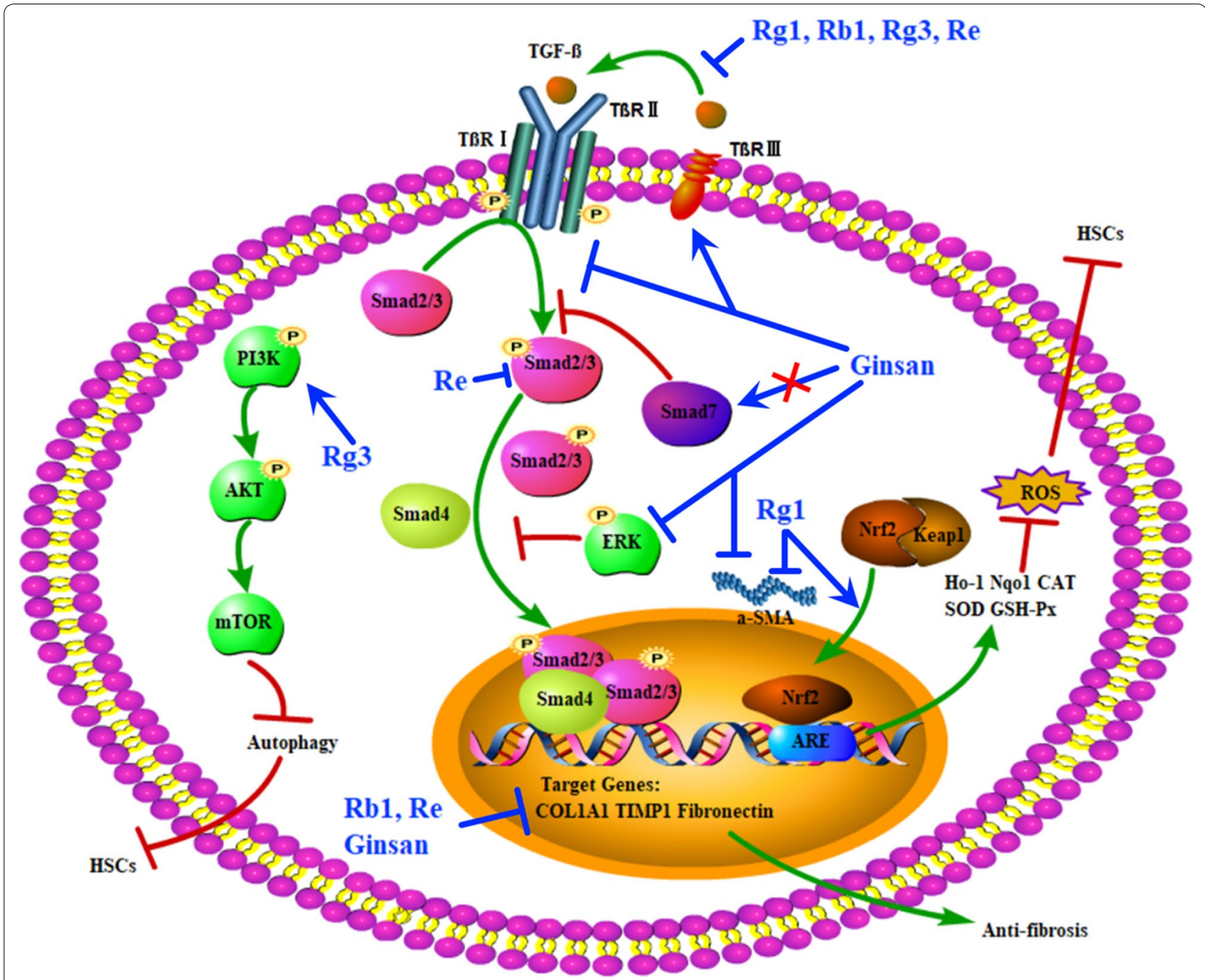

Fig. 3 Schematic diagram summarizing the molecular mechanisms of ginseng components against fibrosis

confirmed whether there will always be beneficial drug interactions. What matter is that patients may experience temporary stomach upset, insomnia, hypertension, or other mild adverse effects after taking an inappropriate dose of ginseng.

Overall, the preliminary experimental evidence in vivo and in vitro supported the therapeutic potential of $P$. ginseng in different organs fibrosis, which has a bearing on anti-inflammation, antioxidant and regulating TGF- $\beta$ /SMAD pathway. However, in order to better apply $P$. ginseng in the clinical practice of OFD and promote the modern development of traditional Chinese medicine represented by ginseng in the treatment of fibrosis, further convincing evidence of the relationship between the all-round mechanisms and the anti-fibrotic activity of $P$. ginseng requires to be provided.

\section{Abbreviations}

8-OHdG: 8-hydroxy-2'-deoxyguanosine; AAC: Abdominal aortic coarctation; ACC: Acetyl-coenzyme Acarboxylase; ACE: Ang converting enzyme; AGE: Advanced glycation end product; AKT: Serine-threonine kinase Akt; ALP: Alkaline phosphatase; ALT: Alanine aminotransferase; AMPK: AMP-activated protein kinase; AMS: Ammonium sulfate; ANF: Atrial natriuretic factor; Ang II: Angiotensin II; ARCP: Extracted adventitious root culture of P ginseng; AST: Aspartate aminotransferase; AT1: Ang II type 1; ATG7: Autophagy related 7; Bax: BCL2-Associated X Protein; BCl-2: B-cell lymphoma-2; BLM: Bleomycin; BNP. Brain natriuretic peptide; BUN: Blood urea nitrogen; CAT: Catalase; Cchord: Chord compliance; $\mathrm{CCl}_{4}$ : Carbon tetrachloride; $\mathrm{Ccr}$ : Creatinine clearance ratio; CD31: Platelet endothelial cell adhesion molecule-1; CFs: Cardiac myofibroblasts; CHM: Chinese herb medicine; CK: Creatine kinase; CK-MB: creatine kinase-MB; Col: Collagen; COX-2: Cyclooxygenase-2; CPT-1: Carnitine palmitoyl transferase-1; Cre: Creatinine; CTGF: Connective tissue growth factor; CVF: Collagen volume fraction; Cx: Connexin; E-CA: E-cadherin; ECM: Extracellular matrix; EMT: Epithelial-mesenchymal transition; ERK: Extracellular signalregulated kinases; ET: Ethanol; FAS: Fatty acid synthase; FGF2: Basic fibroblast growth factor; FN: Fibronectin; FoxO3a: Forkhead box protein O transcription factor 3a; FSP-1: Fibroblast-specific protein 1; FVC: Forced vital capacity; FZHY: Fuzheng Huayu; GGT: Gama-glutamil transferase; Glu: Glucose; GRd: Glutathione reductase; GSH: Glutathione; GST: Glutathione S-transferase; GSX: 
Glutathione peroxidase; $\mathrm{H}_{2} \mathrm{O}_{2}$ : Hydrogen peroxide; $\mathrm{HbA1c}$ : Glycated hemoglobin type A1c; HD: Hesperidin derivative; HDL: High-density lipoprotein; HO-1: Heme oxygenase-1; HSC: Hepatic stellate cells; HSL: Hormone sensitive lipase; HYP: Hydroxyproline; L: Interleukin; INF-Y: Interferon gamma; iNOS: Inducible nitric oxide synthase; IPF: Idiopathic pulmonary fibrosis; IR: Irradiation; ISO: Isoproterenol; JHF: Jinshui Huanxian formula; JNK: c-Jun N-terminal kinase; KIM1: Kidney injury molecule-1; KRG: Korean red ginseng; LAD: Ligating left anterior descending coronary artery; LC3: Microtubule associated protein light chain 3; LDH: Lactate dehydrogenase; LDL: Low-density lipoprotein; LF: Liver fibrosis; LVEDP: Left ventricular end diastolic pressure; LVEF: Left ventricular ejection fraction; LVFS: Left ventricular fractional shortening; LVSP: Left ventricular systolic pressure; MAO: Monoamine; MAPK: Mitogen-activated protein kinase; MBDL: Mild bile duct ligation; MCP-1: Monocyte chemoattractant protein-1; MDA: Malondialdehyde; MF: Myocardial fibrosis; MMP: Matrix metalloproteinase; MnSOD: Manganese superoxide dismutase; MPO: Myeloperoxidase; mTOR: Mammalian target of rapamycin; Myd88: myeloid differentiation primary response gene 88; NDB: Nintedanib; NF-KB: Nuclear factor kappa B; NO: Nitric oxide; NOX4: NADPH oxid4; Nrf2: Nuclear factor erythroid 2-related factor 2; NT-proBNP: N-terminal pro-B-type natriuretic peptide; OFD: Organ fibrosis diseases; PAl-1: Plasminogen activator inhibitor 1; PDGF: Platelet-derived growth factor; PFD: Pirfenidone; PI3K: Phosphatidylinositol 3-kinase; PICP: Propeptide of procollagen type l; PIIINP: Amino terminal propeptide of procollagen type III; PPAR: Peroxisome proliferator-activated receptor; RF: Renal fibrosis; RI: Resistance; ROS: Reactive oxygen species; Scr: Serum creatinine; SGYC: Shenge Yangfei Capsules; Smad: Mothers against decapentaplegic homolog; SMYAD: Si-Miao-Yong-An; SOD: Superoxide dismutase; SQRL: Strengthening Qi and Replenishing Lung; SREBP-1c: Sterol regulatory element binding protein-1c; STZ: Streptozotocin; TAC: Transverse Aortic Constriction; TC: Total cholesterol; TCMF: Traditional Chinese medicine formula; TG: Triglycerides; TGF- $\beta$ : Transforming growth factor $\beta$; TIMP: Tissue inhibitor matrix metalloproteinase; TLC: Total lung capacity; TLR: Toll-like receptor; TNF-a: Tumor necrosis factor-alpha; TP: Total protein; TXL: Tongxinluo; TRR: Transforming growth factor beta receptor; UAER: Urine albumin excretion ratio; UUO: Unilateral ureteral obstruction; WHO: World Health Organization; a-SMA: a-smooth muscle actin.

\section{Acknowledgements}

\section{Not applicable.}

\section{Authors' contributions}

HL proposed the review, wrote the manuscript and designed the figures. $\mathrm{CL}$ and $\mathrm{J} \mathrm{L}$ revised the manuscript. All authors read and approved the final manuscript.

\section{Funding}

This work was granted by the National Key R\&D Program of China

(2017YFC1702302). This work was supported by LiaoNing Revitalization Talents Program (No. XLYC1902119).

\section{Availability of data and materials}

Not applicable.

\section{Ethics approval and consent to participate}

Not applicable.

\section{Consent for publication}

Not applicable.

\section{Competing interests}

The authors declare that they have no competing interests.

\section{Author details}

${ }^{1}$ School of Traditional Chinese Materia Medica, Shenyang Pharmaceutical University, Shenyang 110006 , PR China. ${ }^{2}$ Liaoning Provincial Key Laboratory of TCM Resources Conservation and Development, Shenyang Pharmaceutical University, Shenyang 110006, PR China.

Received: 1 July 2020 Revised: 27 October 2020 Accepted: 6 November 2020

Published online: 24 November 2020

\section{References}

1. Wynn TA. Cellular and molecular mechanisms of fibrosis. J Pathol. 2008;214(2):199-210.

2. Zeisberg M, Kalluri R. Cellular mechanisms of tissue fibrosis. 1. Common and organ-specific mechanisms associated with tissue fibrosis. Am J Physiol Cell Physiol. 2013;304(3):C216-C25.

3. Chen DQ, Feng YL, Cao G, Zhao YY. Natural products as a source for antifibrosis therapy. Trends Pharmacol Sci. 2018;39(11):937-52.

4. Cao M, Yan H, Han X, Weng L, Wei Q, Sun X, et al. Ginseng-derived nanoparticles alter macrophage polarization to inhibit melanoma growth. J Immunother Cancer. 2019;7(1):326.

5. Lee S-T, Chu K, Sim J-Y, Heo J-H, Kim M. Panax ginseng enhances cognitive performance in Alzheimer disease. Alzheimer Dis Assoc Disord. 2008;22(3):222-6.

6. Huang L, Peng Z, Lu C, Chen Y, Lv J-w, Qin M, et al. Ginsenoside Rg, alleviates repeated alcohol exposure-induced psychomotor and cognitive deficits. Chin Med. 2020;15:1-11.

7. Wu L, Zhang AL, Di YM, Shergis JL, Chen Y, Guo X, et al. Panax ginseng therapy for chronic obstructive pulmonary disease: a clinical trial protocol and pilot study. Chin Med. 2014;9(1):20.

8. Riaz M, Rahman NU, Zia-UI-Haq M, Jaffar HZ, Manea R. Ginseng: a dietary supplement as immune-modulator in various diseases. Trends Food Sci Technol. 2019;83:12-30.

9. Zhou X, Seto SW, Chang D, Kiat H, Razmovski-Naumovski V, Chan K, et al. Synergistic effects of Chinese herbal medicine: a comprehensive review of methodology and current research. Front Pharmacol. 2016;7:201.

10. Hariharan S, Mcbride MA, Cherikh WS, Tolleris CB, Bresnahan BA, Johnson CP. Post-transplant renal function in the first year predicts long-term kidney transplant survival. Kidney Int. 2002;62(1):311-8.

11. Sofair AN, Barry V, Manos MM, Thomas A, Zaman A, Terrault NA, et al. The epidemiology and clinical characteristics of patients with newly diagnosed alcohol-related liver disease: results from population-based surveillance. J Clin Gastroenterol. 2010;44(4):301-7.

12. Richeldi L, Cottin V, du Bois RM, Selman M, Kimura T, Bailes Z, et al. Nintedanib in patients with idiopathic pulmonary fibrosis: combined evidence from the TOMORROW and INPULSIS ${ }^{\circledR}$ trials. Respir Med. 2016;113:74-9.

13. Pica-Mattoccia L, Ruppel A, Xia C, Cioli D. Praziquantel and the benzodiazepine Ro 11-3128 do not compete for the same binding sites in schistosomes. Parasitology. 2008;135(1):47-54.

14. Lange CM, Bojunga J, Hofmann WP, Wunder K, Mihm U, Zeuzem S, et al. Severe lactic acidosis during treatment of chronic hepatitis $B$ with entecavir in patients with impaired liver function. Hepatology. 2009;50(6):2001-6.

15. Brilla CG. Regression of myocardial fibrosis in hypertensive heart disease: diverse effects of various antihypertensive drugs. Cardiovasc Res. 2000;46(2):324-31.

16. Díez J, Querejeta R, López B, González A, Larman M, Martínez Ubago JL. Losartan-dependent regression of myocardial fibrosis is associated with reduction of left ventricular chamber stiffness in hypertensive patients. Circulation. 2002;105(21):2512-7.

17. Chan YT, Wang N, Tan HY, Li S, Feng Y. Targeting hepatic stellate cells for the treatment of liver fibrosis by natural products: is it the dawning of a new era? Front Pharmacol. 2020;11:548.

18. Latief U, Ahmad R. Herbal remedies for liver fibrosis: A review on the mode of action of fifty herbs. J Tradit Complement Med. 2018:8(3):352-60.

19. Li H. Advances in anti hepatic fibrotic therapy with Traditional Chinese Medicine herbal formula. J Ethnopharmacol. 2020;251:112442.

20. Chen J, Hu Y, Chen L, Liu W, Mu Y, Liu P. The effect and mechanisms of Fuzheng Huayu formula against chronic liver diseases. Biomed Pharmacother. 2019;114:108846.

21. Zhao Y, Jiang Y, Chen Y, Zhang F, Zhang X, Zhu L, et al. Dissection of mechanisms of Chinese medicinal formula Si-Miao-Yong-an decoction protects against cardiac hypertrophy and fibrosis in isoprenalineinduced heart failure. J Ethnopharmacol. 2020;248:112050.

22. Feng YL, Chen DQ, Vaziri ND, Guo Y, Zhao YY. Small molecule inhibitors of epithelial-mesenchymal transition for the treatment of cancer and fibrosis. Med Res Rev. 2020;40(1):54-78. 
23. Chen X, Li X-F, Chen Y, Zhu S, Li H-D, Chen S-Y, et al. Hesperetin derivative attenuates $\mathrm{CCl}_{4}$-induced hepatic fibrosis and inflammation by Gli-1-dependent mechanisms. Int Immunopharmacol. 2019;76:105838.

24. Sun H, Che Q-M, Zhao X, Pu X-P. Antifibrotic effects of chronic baicalein administration in a $\mathrm{CCl}_{4}$ liver fibrosis model in rats. Eur J Pharmacol. 2010;631(1-3):53-60.

25. Ji Y, Wang T, Wei Z-f, Lu G-X, Xia Y-f, Dai Y. Paeoniflorin, the main active constituent of Paeonia lactiflora roots, attenuates bleomycin-induced pulmonary fibrosis in mice by suppressing the synthesis of type I collagen. J Ethnopharmacol. 2013;149(3):825-32.

26. Chen $\mathrm{H}$, Chen $\mathrm{Q}$, Jiang C-m, Shi G-Y, Sui B-w, Zhang W, et al. Triptolide suppresses paraquat induced idiopathic pulmonary fibrosis by inhibiting TGF- $\beta 1$-dependent epithelial mesenchymal transition. Toxicol Lett. 2018;284:1-9.

27. Jin W, Zhang $Y, X$ ue $Y$, Han $X$, Zhang $X$, Ma Z, et al. Crocin attenuates isoprenaline-induced myocardial fibrosis by targeting TLR4/NF-KB signaling: connecting oxidative stress, inflammation, and apoptosis. Naunyn Schmiedebergs Arch Pharmacol. 2020;393(1):13-23.

28. Wan Y, Xu L, Wang Y, Tuerdi N, Ye M, Qi R. Preventive effects of astragaloside IV and its active sapogenin cycloastragenol on cardiac fibrosis of mice by inhibiting the NLRP3 inflammasome. Eur J Pharmacol. 2018;833:545-54.

29. Lee H, Lee JY, Song KC, Kim J, Park JH, Chun K-H, et al. Protective effect of processed Panax ginseng, sun ginseng on UVB-irradiated human skin keratinocyte and human dermal fibroblast. J Ginseng Res. 2012;36(1):68.

30. Tsukada S, Parsons CJ, Rippe RA. Mechanisms of liver fibrosis. Clin Chim Acta. 2006;364(1):33-60.

31. Hafez MM, Hamed SS, El-Khadragy MF, Hassan ZK, Al Rejaie SS, SayedAhmed MM, et al. Effect of ginseng extract on the TGF- $\beta 1$ signaling pathway in $\mathrm{CCl}_{4}$-induced liver fibrosis in rats. BMC Complement Altern Med. 2017;17(1):1-11.

32. Karakus E, Karadeniz A, Simsek N, Can I, Kara A, Yildirim S, et al. Protective effect of Panax ginseng against serum biochemical changes and apoptosis in liver of rats treated with carbon tetrachloride $\left(\mathrm{CCl}_{4}\right)$. J Hazard Mater. 2011;195:208-13.

33. Nam Y, Ko SK, Sohn UD. Hepatoprotective effect of ultrasonicated ginseng berry extract on a rat mild bile duct ligation model. J Ginseng Res. 2019;43(4):606-17.

34. Murthy HN, Dandin VS, Paek KY. Hepatoprotective activity of ginsenosides from Panax ginseng adventitious roots against carbon tetrachloride treated hepatic injury in rats. J Ethnopharmacol. 2014;158:442-6.

35. Lu K-H, Weng C-Y, Chen W-C, Sheen L-Y. Ginseng essence, a medicinal and edible herbal formulation, ameliorates carbon tetrachlorideinduced oxidative stress and liver injury in rats. J Ginseng Res. 2017:41(3):316-25.

36. Choi S-H, Yang K-J, Lee D-S. Effects of complementary combination therapy of Korean red ginseng and antiviral agents in chronic hepatitis B. J Altern Complement Med. 2016;22(12):964-9.

37. Jang S-A, Lee SR, Koo HJ, Lee JW, Park Y, Namkoong S, et al. Gamma irradiation-induced liver injury and its amelioration by red ginseng extract. Mol Cell Toxicol. 2017;13(4):461-9.

38. Ki SH, Yang JH, Ku SK, Kim SC, Kim YW, Cho IJ. Red ginseng extract protects against carbon tetrachloride-induced liver fibrosis. J Ginseng Res. 2013;37(1):45

39. Lee HJ, Ok HM, Kwon O. Protective effects of Korean Red Ginseng against alcohol-induced fatty liver in rats. Molecules. 2015;20(6):11604-16.

40. Wynn TA. Integrating mechanisms of pulmonary fibrosis. J Exp Med. 2011;208(7):1339-50.

41. Jang SS, Kim HG, Han JM, Lee JS, Choi MK, Huh GJ, et al. Modulation of radiation-induced alterations in oxidative stress and cytokine expression in lung tissue by Panax ginseng extract. Phytother Res. 2015;29(2):201-9.

42. Chen F, Wang P-I, Fan X-s, Yu J-h, Zhu Y, Zhu Z-h. Effect of Renshen Pingfei Decoction, a traditional Chinese prescription, on IPF induced by Bleomycin in rats and regulation of TGF- $\beta 1 / S m a d 3$. J Ethnopharmacol. 2016;186:289-97.

43. Bai Y, Li J, Zhao P, Li Y, Li M, Feng S, et al. A Chinese herbal formula ameliorates pulmonary fibrosis by inhibiting oxidative stress via upregulating Nrf2. Front Pharmacol. 2018;9:628.
44. Jia H, Wang Z-j, Wu Q, Xu Z-r, Zhang J-y, Zhao Q-c. Antifibrosis effects of Shenge Yangfei Capsules on bleomycin-induced pulmonary fibrosis in rats. Chin Herb Med. 2018;10(4):411-5.

45. Zhang H-Q, Yau Y-F, Wong M-S, Man O-Y, He Y-Y, Chan N, et al. Chinese medicine formula DSQRL versus glucocorticoids for the treatment of experimental pulmonary fibrosis. J Ethnopharmacol. 2008;116(2):318-24.

46. Liu T, Song D, Dong J, Zhu P, Liu J, Liu W, et al. Current understanding of the pathophysiology of myocardial fibrosis and its quantitative assessment in heart failure. Front Physiol. 2017;8:238.

47. Zhang C-L, Li Y-H, Zhou H-X, Zhang Y-X, Wang Y-S, Zhang Z-Y, et al. Protective effects of Ginseng mixture on myocardial fibrosis in rats. Asian Pac J Trop Med. 2014;7(9):730-4.

48. Lim KH, Ko D, Kim J-H. Cardioprotective potential of Korean Red Ginseng extract on isoproterenol-induced cardiac injury in rats. J Ginseng Res. 2013;37(3):273.

49. Ma J, Yin C, Ma S, Qiu H, Zheng C, Chen Q, et al. Shensong Yangxin capsule reduces atrial fibrillation susceptibility by inhibiting atrial fibrosis in rats with post-myocardial infarction heart failure. Drug Des Devel Ther. 2018;12:3407.

50. Wang X, Mu C, Mu T, Gao L, Zhao Y, Zhang Y, et al. Effects of Tongxinluo on myocardial fibrosis in diabetic rats. J Chinese Med Association. 2016;79(3):130-6.

51. Ma J, Ma S, Yin C, Wu H. Shengmai San-derived herbal prevents the development of a vulnerable substrate for atrial fibrillation in a rat model of ischemic heart failure. Biomed Pharmacother. 2018;100:156-67.

52. Ma S, Li X, Dong L, Zhu J, Zhang H, Jia Y. Protective effect of Sheng-Mai Yin, a traditional Chinese preparation, against doxorubicin-induced cardiac toxicity in rats. BMC Complement Altern Med. 2016;16(1):61.

53. Pang L-Z, Ju A-C, Zheng X-j, Li F, Song Y-f, Zhao Y, et al. YiQiFuMai powder injection attenuates coronary artery ligation-induced myocardial remodeling and heart failure through modulating MAPKs signaling pathway. J Ethnopharmacol. 2017;202:67-77.

54. Liu Y. Cellular and molecular mechanisms of renal fibrosis. Nat Rev Nephrol. 2011;7(12):684.

55. Kalkan Y, Kapakin KAT, Kara A, Atabay T, Karadeniz A, Simsek N, et al. Protective effect of Panax ginseng against serum biochemical changes and apoptosis in kidney of rats treated with gentamicin sulphate. J Mol Histol. 2012:43(5):603-13.

56. Choi HJ, Kim EJ, Shin YW, Park JH, Kim D-H, Kim NJ. Protective effect of heat-processed ginseng (sun ginseng) in the adenine-induced renal failure rats. J Ginseng Res. 2012;36(3):270.

57. Karunasagara S, Hong G-L, Park S-R, Lee N-H, Jung D-Y, Kim TW, et al. Korean red ginseng attenuates hyperglycemia-induced renal inflammation and fibrosis via accelerated autophagy and protects against diabetic kidney disease. J Ethnopharmacol. 2020:112693.

58. Lim SW, Shin YJ, Luo K, Quan Y, Cui S, Ko EJ, et al. Ginseng increases Klotho expression by FoxO3-mediated manganese superoxide dismutase in a mouse model of tacrolimus-induced renal injury. Aging. 2019;11(15):5548.

59. Kim C-S, Jo K, Kim JS, Pyo M-K, Kim J. GS-E3D, a new pectin lyase-modified red ginseng extract, inhibited diabetes-related renal dysfunction in streptozotocin-induced diabetic rats. BMC Complement Altern Med. 2017;17(1):430.

60. Wu XM, Gao YB, Xu LP, Zou DW, Zhu ZY, Wang XL, et al. Tongxinluo inhibits renal fibrosis in diabetic nephropathy: involvement of the suppression of intercellular transfer of TGF- $\beta 1$-containing exosomes from GECs to GMCs. Am J Chin Med. 2017;45(5):1075-92.

61. Li X, Mo N, Li ZZ. Ginsenosides: potential therapeutic source for fibrosisassociated human diseases. J Ginseng Res. 2020;44(3):386-98.

62. Li JP, Gao Y, Chu SF, Zhang Z, Xia CY, Mou Z, et al. Nrf2 pathway activation contributes to anti-fibrosis effects of ginsenoside $\mathrm{Rg}_{1}$ in a rat model of alcohol- and $\mathrm{CCl}_{4}$-induced hepatic fibrosis. Acta Pharmacol Sin. 2014;35:1031-44.

63. Zhan H, Huang F, Ma WZ, Zhao ZH, Zhang HF, Zhang C. Protective effect of Ginsenoside $\mathrm{Rg}_{1}$ on bleomycin-induced pulmonary fibrosis in rats: Involvement of Caveolin-1 and TGF- $\beta 1$ signal pathway. Biol Pharm Bull. 2016;39(8):1284-92.

64. Zhang YJ, Zhang XL, Li MH, lqbal J, Bourantas CV, Li JJ, et al. The ginsenoside $\mathrm{Rg}_{1}$ prevents transverse aortic constriction-induced left ventricular 
hypertrophy and cardiac dysfunction by inhibiting fibrosis and enhancing angiogenesis. J Cardiovasc Pharmacol. 2013;62(1):50-7.

65. Xie XS, Liu HC, Wang FP, Zhang CL, Zuo C, Deng Y, et al. Ginsenoside Rg, modulation on thrombospondin-1 and vascular endothelial growth factor expression in early renal fibrogenesis in unilateral obstruction. Phytother Res. 2010;24(11):1581-7.

66. Hou YL, Tsai YH, Lin YH, Chao JC. Ginseng extract and ginsenoside Rb, attenuate carbon tetrachloride-induced liver fibrosis in rats. BMC Complement Altern Med. 2014;14(1):415.

67. Zheng $X$, Wang S, Zou X, Jing Y, Yang R, Li S, et al. Ginsenoside Rb, improves cardiac function and remodeling in heart failure. Exp Anim. 2017;66:217-28.

68. Xie XS, Liu HC, Yang M, Zuo C, Deng Y, Fan JM. Ginsenoside Rb , a panoxadiol saponin against oxidative damage and renal interstitial fibrosis in rats with unilateral ureteral obstruction. Chin J Integr Med. 2009;15(2):133-40.

69. Wang QW, Yu XF, Xu HL, Zhao XZ, Sui DY. Ginsenoside Re improves isoproterenol-induced myocardial fibrosis and heart failure in rats. Evid Based Complement Alternat Med. 2019;2019:3714508.

70. Liu XX, Mi XJ, Wang Z, Zhang M, Hou JG, Jiang S, et al. Ginsenoside $\mathrm{Rg}_{3}$ promotes regression from hepatic fibrosis through reducing inflammation-mediated autophagy signaling pathway. Cell Death Dis. 2020;11(6):454.

71. Hong SH, Hwang HJ, Kim JW, Kim JA, Lee YB, Roh E, et al. Ginsenoside compound-MC attenuates oxidative stress and apoptosis in cardiomyocytes through an AMP-activated protein kinase-dependent mechanism. J Ginseng Res. 2020;44(4):664-71.
72. Ahn JY, Kim MH, Lim MJ, Park S, Lee Slo, Yun YS, et al. The inhibitory effect of ginsan on TGF- $\beta$ mediated fibrotic process. J Cell Physiol. 2011;226(5):1241-7.

73. Jiang R, Xu X, Sun Z, Wang F, Ma R, Feng K, et al. Protective effects of ginseng proteins on photoaging of mouse fibroblasts induced by UVA. Photochem Photobiol. 2020;96(1):113-23.

74. Wang W, Wang S, Liu J, Cai E, Zhu H, He Z, et al. Sesquiterpenoids from the root of Panax Ginseng protect $\mathrm{CCl}_{4}$-induced acute liver injury by antiinflammatory and anti-oxidative capabilities in mice. Biomed Pharmacother. 2018;102:412-9.

75. Mathur S, Hoskins C. Drug development: Lessons from nature. Biomed Rep. 2017;6(6):612-4.

76. Du N, Xu ZP, Gao MY, Liu P, Sun B, Cao X. Combination of Ginsenoside Rg and Astragaloside IV reduces oxidative stress and inhibits TGF- $\beta 1 / S$ mads signaling cascade on renal fibrosis in rats with diabetic nephropathy. Drug Des Devel Ther. 2018;12:3517.

\section{Publisher's Note}

Springer Nature remains neutral with regard to jurisdictional claims in published maps and institutional affiliations.
Ready to submit your research? Choose BMC and benefit from:

- fast, convenient online submission

- thorough peer review by experienced researchers in your field

- rapid publication on acceptance

- support for research data, including large and complex data types

- gold Open Access which fosters wider collaboration and increased citations

- maximum visibility for your research: over $100 \mathrm{M}$ website views per year

At BMC, research is always in progress.

Learn more biomedcentral.com/submissions 